\title{
Fixed point results via $\alpha$-admissible mappings and cyclic contractive mappings in partial $b$-metric spaces
}

\section{Abdul Latif**, Jamal Rezaei Roshan², Vahid Parvaneh³ and Nawab Hussain}

"Correspondence: alatif@kau.edu.sa 'Department of Mathematics, King Abdulaziz University, P.O. Box 80203, Jeddah, 21589, Saudi Arabia Full list of author information is available at the end of the article

\begin{abstract}
Considering $\alpha$-admissible mappings in the setup of partial $b$-metric spaces, we establish some fixed and common fixed point results for ordered cyclic weakly $(\psi, \varphi, L, A, B)$-contractive mappings in complete ordered partial $b$-metric spaces. Our results extend several known results in the literature. Examples are also provided in support of our results.

MSC: Primary $47 \mathrm{H} 10$; secondary $54 \mathrm{H} 25$

Keywords: fixed point; generalized weakly contraction; partial metric space; partially weakly increasing mappings; altering distance function
\end{abstract}

\section{Introduction}

There are a lot of generalizations of the concept of metric space. The concepts of $b$-metric space and partial metric space were introduced by Czerwik [1] and Matthews [2], respectively. Combining these two notions, Shukla [3] introduced another generalization which is called a partial $b$-metric space. Also, in [4], Mustafa et al. introduced a modified version of partial $b$-metric spaces. In fact, the advantage of their definition of partial $b$-metric is that by using it one can define a dependent $b$-metric which is called the $b$-metric associated with the partial $b$-metric.

Definition 1.1 [4] Let $X$ be a (nonempty) set and $s \geq 1$ be a given real number. A function $p_{b}: X \times X \rightarrow \mathbb{R}^{+}$is a partial $b$-metric if, for all $x, y, z \in X$, the following conditions are satisfied:

$\left(p_{b 1}\right) x=y \Longleftrightarrow p_{b}(x, x)=p_{b}(x, y)=p_{b}(y, y)$

$\left(p_{b 2}\right) p_{b}(x, x) \leq p_{b}(x, y)$,

$\left(p_{b 3}\right) p_{b}(x, y)=p_{b}(y, x)$,

$\left(p_{b 4}\right) p_{b}(x, y) \leq s\left(p_{b}(x, z)+p_{b}(z, y)-p_{b}(z, z)\right)+\left(\frac{1-s}{2}\right)\left(p_{b}(x, x)+p_{b}(y, y)\right)$.

The pair $\left(X, p_{b}\right)$ is called a partial $b$-metric space.

Example 1.2 [3] Let $X=\mathbb{R}^{+}, q>1$ be a constant, and $p_{b}: X \times X \rightarrow \mathbb{R}^{+}$be defined by

$$
p_{b}(x, y)=[\max \{x, y\}]^{q}+|x-y|^{q} \quad \text { for all } x, y \in X .
$$

(c) 2014 Latif et al.; licensee Springer. This is an Open Access article distributed under the terms of the Creative Commons Attribution License (http://creativecommons.org/licenses/by/2.0), which permits unrestricted use, distribution, and reproduction in any medium, provided the original work is properly cited. 
Then $\left(X, p_{b}\right)$ is a partial $b$-metric space with the coefficient $s=2^{q-1}>1$, but it is neither a $b$-metric nor a partial metric space.

Some more examples of partial $b$-metrics can be constructed with the help of following propositions.

Proposition 1.3 [3] Let $X$ be a nonempty set and let $p$ be a partial metric and $d$ be a $b$-metric with the coefficient $s \geq 1$ on $X$. Then the function $p_{b}: X \times X \rightarrow \mathbb{R}^{+}$defined by $p_{b}(x, y)=p(x, y)+d(x, y)$, for all $x, y \in X$, is a partial b-metric on $X$ with the coefficient s.

Proposition 1.4 [3] Let $(X, p)$ be a partial metric space and $q \geq 1$. Then $\left(X, p_{b}\right)$ is a partial $b$-metric space with the coefficient $s=2^{q-1}$, where $p_{b}$ is defined by $p_{b}(x, y)=[p(x, y)]^{q}$.

Proposition $1.5[4]$ Every partial b-metric $p_{b}$ defines a $b$-metric $d_{p_{b}}$, where

$$
d_{p_{b}}(x, y)=2 p_{b}(x, y)-p_{b}(x, x)-p_{b}(y, y)
$$

for all $x, y \in X$.

Now, we recall some definitions and propositions in a partial $b$-metric space.

Definition 1.6 [4] Let $\left(X, p_{b}\right)$ be a partial $b$-metric space. Then for an $x \in X$ and an $\epsilon>0$, the $p_{b}$-ball with center $x$ and radius $\epsilon$ is

$$
B_{p_{b}}(x, \epsilon)=\left\{y \in X \mid p_{b}(x, y)<p_{b}(x, x)+\epsilon\right\} .
$$

Proposition 1.7 [4] Let $\left(X, p_{b}\right)$ be a partial b-metric space, $x \in X$, and $r>0$. If $y \in B_{p_{b}}(x, r)$ then there exists $a \delta>0$ such that $B_{p_{b}}(y, \delta) \subseteq B_{p_{b}}(x, r)$.

Thus, from the above proposition the family of all $p_{b}$-balls

$$
\Delta=\left\{B_{p_{b}}(x, r) \mid x \in X, r>0\right\}
$$

is a base of a $T_{0}$ topology $\tau_{p_{b}}$ on $X$ which we call the $p_{b}$-metric topology.

The topological space $\left(X, p_{b}\right)$ is $T_{0}$, but it does not need to be $T_{1}$.

Definition 1.8 [4] A sequence $\left\{x_{n}\right\}$ in a partial $b$-metric space $\left(X, p_{b}\right)$ is said to be:

(i) $p_{b}$-convergent to a point $x \in X$ if $\lim _{n \rightarrow \infty} p_{b}\left(x, x_{n}\right)=p_{b}(x, x)$.

(ii) A $p_{b}$-Cauchy sequence if $\lim _{n, m \rightarrow \infty} p_{b}\left(x_{n}, x_{m}\right)$ exists (and is finite).

(iii) A partial $b$-metric space $\left(X, p_{b}\right)$ is said to be $p_{b}$-complete if every $p_{b}$-Cauchy sequence $\left\{x_{n}\right\}$ in $X p_{b}$-converges to a point $x \in X$ such that $\lim _{n, m \rightarrow \infty} p_{b}\left(x_{n}, x_{m}\right)=\lim _{n, m \rightarrow \infty} p_{b}\left(x_{n}, x\right)=p_{b}(x, x)$.

\section{Lemma 1.9 [4]}

(1) A sequence $\left\{x_{n}\right\}$ is a $p_{b}$-Cauchy sequence in a partial b-metric space $\left(X, p_{b}\right)$ if and only if it is a $b$-Cauchy sequence in the $b$-metric space $\left(X, d_{p_{b}}\right)$. 
(2) A partial $b$-metric space $\left(X, p_{b}\right)$ is $p_{b}$-complete if and only if the $b$-metric space $\left(X, d_{p_{b}}\right)$ is b-complete. Moreover, $\lim _{n \rightarrow \infty} d_{p_{b}}\left(x, x_{n}\right)=0$ if and only if

$$
\lim _{n \rightarrow \infty} p_{b}\left(x, x_{n}\right)=\lim _{n, m \rightarrow \infty} p_{b}\left(x_{n}, x_{m}\right)=p_{b}(x, x) .
$$

Definition $1.10[4]$ Let $\left(X, p_{b}\right)$ and $\left(X^{\prime}, p_{b}^{\prime}\right)$ be two partial $b$-metric spaces and let $f$ : $\left(X, p_{b}\right) \rightarrow\left(X^{\prime}, p_{b}^{\prime}\right)$ be a mapping. Then $f$ is said to be $p_{b}$-continuous at a point $a \in X$ if for a given $\varepsilon>0$, there exists $\delta>0$ such that $x \in X$ and $p_{b}(a, x)<\delta+p_{b}(a, a)$ imply that $p_{b}^{\prime}(f(a), f(x))<\varepsilon+p_{b}^{\prime}(f(a), f(a))$. The mapping $f$ is $p_{b}$-continuous on $X$ if it is $p_{b}$-continuous at all $a \in X$.

Proposition 1.11 [4] Let $\left(X, p_{b}\right)$ and $\left(X^{\prime}, p_{b}^{\prime}\right)$ be two partial b-metric spaces. Then a mapping $f: X \rightarrow X^{\prime}$ is $p_{b}$-continuous at a point $x \in X$ if and only if it is $p_{b}$-sequentially continuous at $x$; that is, whenever $\left\{x_{n}\right\}$ is $p_{b}$-convergent to $x,\left\{f\left(x_{n}\right)\right\}$ is $p_{b}^{\prime}$-convergent to $f(x)$.

Definition 1.12 A triple $\left(X, \preceq, p_{b}\right)$ is called an ordered partial $b$-metric space if $(X, \preceq)$ is a partially ordered set and $p_{b}$ is a partial $b$-metric on $X$.

The following crucial lemma is useful in proving our main results.

Lemma 1.13 [4] Let $\left(X, p_{b}\right)$ be a partial b-metric space with the coefficient $s>1$ and suppose that $\left\{x_{n}\right\}$ and $\left\{y_{n}\right\}$ are convergent to $x$ and $y$, respectively. Then we have

$$
\begin{aligned}
\frac{1}{s^{2}} p_{b}(x, y)-\frac{1}{s} p_{b}(x, x)-p_{b}(y, y) & \leq \liminf _{n \rightarrow \infty} p_{b}\left(x_{n}, y_{n}\right) \leq \limsup _{n \rightarrow \infty} p_{b}\left(x_{n}, y_{n}\right) \\
& \leq s p_{b}(x, x)+s^{2} p_{b}(y, y)+s^{2} p_{b}(x, y) .
\end{aligned}
$$

In particular, if $p_{b}(x, y)=0$, then we have $\lim _{n \rightarrow \infty} p_{b}\left(x_{n}, y_{n}\right)=0$.

Moreover, for each $z \in X$ we have

$$
\begin{aligned}
\frac{1}{s} p_{b}(x, z)-p_{b}(x, x) & \leq \liminf _{n \rightarrow \infty} p_{b}\left(x_{n}, z\right) \leq \limsup _{n \rightarrow \infty} p_{b}\left(x_{n}, z\right) \\
& \leq s p_{b}(x, z)+s p_{b}(x, x) .
\end{aligned}
$$

In particular, if $p_{b}(x, x)=0$, then we have

$$
\frac{1}{s} p_{b}(x, z) \leq \liminf _{n \rightarrow \infty} p_{b}\left(x_{n}, z\right) \leq \limsup _{n \rightarrow \infty} p_{b}\left(x_{n}, z\right) \leq s p_{b}(x, z) .
$$

One of the interesting generalizations of the Banach contraction principle was given by Kirk et al. [5] in 2003 by introducing the notion of cyclic representation.

Definition 1.14 [5] Let $A$ and $B$ be nonempty subsets of a metric space $(X, d)$ and $T$ : $A \cup B \rightarrow A \cup B$. Then $T$ is called a cyclic map if $T(A) \subseteq B$ and $T(B) \subseteq A$.

The following interesting theorem for a cyclic map was given in [5]. 
Theorem 1.15 [5] Let $A$ and $B$ be nonempty closed subsets of a complete metric space $(X, d)$. Suppose that $T: A \cup B \rightarrow A \cup B$ is a cyclic map such that

$$
d(T x, T y) \leq k d(x, y)
$$

for all $x \in A$ and $y \in B$, where $k \in[0,1)$ is a constant. Then $T$ has a unique fixed point $u$ and $u \in A \cap B$.

Berinde initiated in $[6,7]$ the concept of almost contractions and obtained several interesting fixed point theorems for Ćirić strong almost contractions. Babu et al. introduced in [8] the class of mappings which satisfy 'condition $(B)$ '. Moreover, they proved the existence of fixed points for such mappings on complete metric spaces. Finally, Cirić et al. in [9], and Aghajani et al. in [10] introduced the concept of almost generalized contractive conditions (for two, resp. four mappings) and proved some important results in ordered metric spaces. Let us recall one of these definitions.

Definition 1.16 [9] Let $f$ and $g$ be two self-mappings on a metric space $(X, d)$. They are said to satisfy almost generalized contractive condition, if there exist a constant $\delta \in(0,1)$ and some $L \geq 0$ such that

$$
\begin{aligned}
d(f x, g y) \leq & \delta \max \left\{d(x, y), d(x, f x), d(y, g y), \frac{d(x, g y)+d(y, f x)}{2}\right\} \\
& +L \min \{d(x, f x), d(y, g y), d(x, g y), d(y, f x)\},
\end{aligned}
$$

for all $x, y \in X$.

Definition 1.17 [11] A function $\varphi:[0, \infty) \rightarrow[0, \infty)$ is called an altering distance function, if the following properties hold:

(1) $\varphi$ is continuous and nondecreasing.

(2) $\varphi(t)=0$ if and only if $t=0$.

Definition 1.18 [12] Let $(X, \preceq)$ be a partially ordered set and $A$ and $B$ be closed subsets of $X$ with $X=A \cup B$. Let $f, g: X \rightarrow X$ be two mappings. The pair $(f, g)$ is said to be $(A, B)$ weakly increasing if $f x \preceq g f x$, for all $x \in A$ and $g y \preceq f g y$, for all $y \in B$.

In [13], Hussain et al. introduced the notion of ordered cyclic weakly $(\psi, \varphi, L, A, B)$ contractive pair of self-mappings as follows.

Definition 1.19 [13] Let $(X, \preceq, d)$ be an ordered $b$-metric space, let $f, g: X \rightarrow X$ be two mappings, and let $A$ and $B$ be nonempty closed subsets of $X$. The pair $(f, g)$ is called an ordered cyclic weakly $(\psi, \varphi, L, A, B)$-contraction if

(1) $X=A \cup B$ is a cyclic representation of $X$ w.r.t. the pair $(f, g)$; that is, $f A \subseteq B$ and $g B \subseteq A$

(2) there exist two altering distance functions $\psi, \varphi$ and a constant $L \geq 0$, such that for arbitrary comparable elements $x, y \in X$ with $x \in A$ and $y \in B$, we have

$$
\psi\left(s^{2} d(f x, g y)\right) \leq \psi\left(M_{s}(x, y)\right)-\varphi\left(M_{s}(x, y)\right)+L \psi(N(x, y))
$$


where

$$
M_{s}(x, y)=\max \left\{d(x, y), d(x, f x), d(y, g y), \frac{d(x, g y)+d(y, f x)}{2 s}\right\}
$$

and

$$
N(x, y)=\min \{d(x, f x), d(y, g y), d(x, g y), d(y, f x)\} .
$$

Also, in [13] the authors proved the following results.

Theorem 1.20 [13] Let $(X, \preceq, d)$ be a complete ordered b-metric space and $A$ and $B$ be closed subsets of $X$. Let $f, g: X \rightarrow X$ be two $(A, B)$-weakly increasing mappings with respect to $\preceq$. Suppose that:

(a) the pair $(f, g)$ is an ordered cyclic weakly $(\psi, \varphi, L, A, B)$-contraction;

(b) $f$ or $g$ is continuous.

Then $f$ and $g$ have a common fixed point $u \in A \cap B$.

An ordered $b$-metric space $(X, \preceq, d)$ is called regular if for any nondecreasing sequence $\left\{x_{n}\right\}$ in $X$ such that $x_{n} \rightarrow x \in X$, as $n \rightarrow \infty$, one has $x_{n} \preceq x$ for all $n \in \mathbb{N}$.

Theorem 1.21 [13] Let the hypotheses of Theorem 1.20 be satisfied, except that condition

(b) is replaced by the assumption

$\left(\mathrm{b}^{\prime}\right)$ the space $(X, \preceq, d)$ is regular.

Then $f$ and $g$ have a common fixed point in $X$.

In this paper, first we prove some fixed point results for $\alpha$-admissible mappings in the context of partial $b$-metric spaces. Then we express some common fixed point results for cyclic generalized almost contractive mappings. Our results extend and generalize some recent results in [4] and [13]. In fact, they are cyclic variants of the results in [4].

\section{Fixed point results via $\alpha$-admissible mappings in partial $\boldsymbol{b}$-metric spaces}

Samet et al. [14] defined the notion of $\alpha$-admissible mappings and proved the following result.

Definition 2.1 [14] Let $T$ be a self-mapping on $X$ and $\alpha: X \times X \rightarrow[0, \infty)$ be a function. We say that $T$ is an $\alpha$-admissible mapping if

$$
x, y \in X, \quad \alpha(x, y) \geq 1 \quad \Longrightarrow \quad \alpha(T x, T y) \geq 1 .
$$

Denote by $\Psi^{\prime}$ the family of all nondecreasing functions $\psi:[0, \infty) \rightarrow[0, \infty)$ such that $\sum_{n=1}^{\infty} \psi^{n}(t)<\infty$ for all $t>0$, where $\psi^{n}$ is the $n$th iterate of $\psi$.

Theorem 2.2 [14] Let $(X, d)$ be a complete metric space and $T$ be an $\alpha$-admissible mapping. Assume that

$$
\alpha(x, y) d(T x, T y) \leq \psi(d(x, y))
$$


where $\psi \in \Psi^{\prime}$. Also, suppose that the following assertions hold:

(i) there exists $x_{0} \in X$ such that $\alpha\left(x_{0}, T x_{0}\right) \geq 1$;

(ii) either $T$ is continuous or for any sequence $\left\{x_{n}\right\}$ in $X$ with $\alpha\left(x_{n}, x_{n+1}\right) \geq 1$ for all $n \in \mathbb{N} \cup\{0\}$ such that $x_{n} \rightarrow x$ as $n \rightarrow \infty$, we have $\alpha\left(x_{n}, x\right) \geq 1$ for all $n \in \mathbb{N} \cup\{0\}$.

Then $T$ has a fixed point.

We now recall the concept of $(c)$-comparison function which was introduced by Berinde [15].

Definition 2.3 (Berinde [15]) A function $\varphi:[0, \infty) \rightarrow[0, \infty)$ is said to be a (c)-comparison function if

$\left(c_{1}\right) \varphi$ is increasing,

$\left(c_{2}\right)$ there exist $k_{0} \in \mathbb{N}, a \in(0,1)$, and a convergent series of nonnegative terms $\sum_{k=1}^{\infty} v_{k}$ such that $\varphi^{k+1}(t) \leq a \varphi^{k}(t)+v_{k}$, for $k \geq k_{0}$ and any $t \in[0, \infty)$.

Later, Berinde [16] introduced the notion of (b)-comparison function as a generalization of a (c)-comparison function.

Definition 2.4 (Berinde [16]) Let $s \geq 1$ be a real number. A mapping $\varphi:[0, \infty) \rightarrow[0, \infty)$ is called a $(b)$-comparison function if the following conditions are fulfilled:

(1) $\varphi$ is monotone increasing;

(2) there exist $k_{0} \in \mathbb{N}, a \in(0,1)$, and a convergent series of nonnegative terms $\sum_{k=1}^{\infty} v_{k}$ such that $s^{k+1} \varphi^{k+1}(t) \leq a s^{k} \varphi^{k}(t)+v_{k}$, for $k \geq k_{0}$ and any $t \in[0, \infty)$.

Let $\Psi_{b}$ be the class of $(b)$-comparison functions $\varphi:[0, \infty) \rightarrow[0, \infty)$. It is clear that the notion of $(b)$-comparison function coincides with (c)-comparison function for $s=1$.

We now recall the following lemma, which will simplify the proofs.

Lemma 2.5 (Berinde [17]) If $\varphi:[0, \infty) \rightarrow[0, \infty)$ is a (b)-comparison function, then we have the following.

(1) the series $\sum_{k=0}^{\infty} s^{k} \varphi^{k}(t)$ converges for any $t \in \mathbb{R}_{+}$;

(2) the function $b_{s}:[0, \infty) \rightarrow[0, \infty)$, defined by $b_{s}(t)=\sum_{k=0}^{\infty} s^{k} \varphi^{k}(t), t \in[0, \infty)$, is increasing and continuous at 0 .

Theorem 2.6 Let $\left(X, p_{b}\right)$ be a $p_{b}$-complete partial b-metric space, $f$ be a continuous $\alpha$ admissible mapping on $X$, there exists $x_{0} \in X$ such that $\alpha\left(x_{0}, f x_{0}\right) \geq 1$ and if any sequence $\left\{x_{n}\right\}$ in $X p_{b}$-converges to a point $x$, where $\alpha\left(x_{n}, x_{n+1}\right) \geq 1$ for all $n$, then we have $\alpha(x, x) \geq 1$. Assume that

$$
s \alpha(x, y) p_{b}(f x, f y) \leq \psi\left(M_{s}(x, y)\right)
$$

for all $x, y \in X$, where $\psi \in \Psi_{b}$ and

$$
M_{s}(x, y)=\max \left\{d(x, y), d(x, f x), d(y, f y), \frac{d(x, f y)+d(f x, y)}{2 s}\right\} .
$$

Then $f$ has a fixed point. 
Proof Let $x_{0} \in X$ be such that $\alpha\left(x_{0}, f x_{0}\right) \geq 1$. Define a sequence $\left\{x_{n}\right\}$ by $x_{n}=f^{n} x_{0}$ for all $n \in \mathbb{N}$. Since $f$ is an $\alpha$-admissible mapping and $\alpha\left(x_{0}, x_{1}\right)=\alpha\left(x_{0}, f x_{0}\right) \geq 1$, we deduce that $\alpha\left(x_{1}, x_{2}\right)=\alpha\left(f x_{0}, f x_{1}\right) \geq 1$. Continuing this process, we get that $\alpha\left(x_{n}, x_{n+1}\right) \geq 1$ for all $n \in$ $\mathbb{N} \cup\{0\}$.

Now, we will finish the proof in the following steps.

First, we prove that

$$
p_{b}\left(x_{n}, x_{n+1}\right) \leq \psi\left(p_{b}\left(x_{n-1}, x_{n}\right)\right)
$$

for each $n=1,2,3, \ldots$.

If $x_{n}=x_{n+1}$, for some $n \in \mathbb{N}$, then $x_{n}=f x_{n}$. Thus, $x_{n}$ is a fixed point of $f$. Therefore, we assume that $x_{n} \neq x_{n+1}$, for all $n \in \mathbb{N}$.

Using condition (2.2) as $\alpha\left(x_{n-1}, x_{n}\right) \geq 1$ for all $n \in \mathbb{N} \cup\{0\}$, we obtain

$$
s p_{b}\left(x_{n}, x_{n+1}\right) \leq s \alpha\left(x_{n-1}, x_{n}\right) p_{b}\left(f x_{n-1}, f x_{n}\right) \leq \psi\left(M_{s}\left(x_{n-1}, x_{n}\right)\right) .
$$

Here,

$$
\begin{aligned}
& M_{s}\left(x_{n-1}, x_{n}\right) \\
& \quad=\max \left\{p_{b}\left(x_{n-1}, x_{n}\right), p_{b}\left(x_{n-1}, f x_{n-1}\right), p_{b}\left(x_{n}, f x_{n}\right), \frac{1}{2 s}\left[p_{b}\left(x_{n-1}, f x_{n}\right)+p_{b}\left(x_{n}, f x_{n-1}\right)\right]\right\} \\
& \quad=\max \left\{p_{b}\left(x_{n-1}, x_{n}\right), p_{b}\left(x_{n-1}, x_{n}\right), p_{b}\left(x_{n}, x_{n+1}\right), \frac{1}{2 s}\left[p_{b}\left(x_{n-1}, x_{n+1}\right)+p_{b}\left(x_{n}, x_{n}\right)\right]\right\} \\
& \quad \leq \max \left\{p_{b}\left(x_{n-1}, x_{n}\right), p_{b}\left(x_{n}, x_{n+1}\right)\right\} .
\end{aligned}
$$

If $p_{b}\left(x_{n}, x_{n+1}\right) \geq p_{b}\left(x_{n-1}, x_{n}\right)$, then

$$
M_{s}\left(x_{n-1}, x_{n}\right) \leq p_{b}\left(x_{n}, x_{n+1}\right)
$$

which yields

$$
s p_{b}\left(x_{n}, x_{n+1}\right) \leq \psi\left(p_{b}\left(x_{n}, x_{n+1}\right)\right)<p_{b}\left(x_{n}, x_{n+1}\right),
$$

a contradiction.

Hence,

$$
p_{b}\left(x_{n}, x_{n+1}\right) \leq \psi\left(p_{b}\left(x_{n-1}, x_{n}\right)\right) .
$$

So (2.3) holds.

By induction, we get

$$
\begin{aligned}
p_{b}\left(x_{n}, x_{n+1}\right) & \leq \psi\left(p_{b}\left(x_{n-1}, x_{n}\right)\right) \\
& \leq \psi^{2}\left(p_{b}\left(x_{n-2}, x_{n-1}\right)\right) \leq \cdots \leq \psi^{n}\left(p_{b}\left(x_{0}, x_{1}\right)\right) .
\end{aligned}
$$


Then, by the triangular inequality and (2.4), we get

$$
\begin{aligned}
p_{b}\left(x_{n}, x_{m}\right) & \leq s p_{b}\left(x_{n}, x_{n+1}\right)+s^{2} p_{b}\left(x_{n+1}, x_{n+2}\right)+\cdots+s^{m-n-1} p_{b}\left(x_{m-1}, x_{m}\right) \\
& \leq \sum_{k=n}^{m-2} s^{k-n+1} \psi^{k}\left(p_{b}\left(x_{0}, x_{1}\right)\right) \\
& \leq \sum_{k=n}^{\infty} s^{k} \psi^{k}\left(p_{b}\left(x_{0}, x_{1}\right)\right) \longrightarrow 0
\end{aligned}
$$

as $n \longrightarrow \infty$.

Since $\left\{x_{n}\right\}$ is a $p_{b}$-Cauchy sequence in the $p_{b}$-complete partial $b$-metric space $X$, from Lemma $1.9,\left\{x_{n}\right\}$ is a $b$-Cauchy sequence in the $b$-metric space $\left(X, d_{p_{b}}\right) \cdot p_{b}$-Completeness of $\left(X, p_{b}\right)$ shows that $\left(X, d_{p_{b}}\right)$ is also $b$-complete. Then there exists $z \in X$ such that

$$
\lim _{n \rightarrow \infty} d_{p_{b}}\left(x_{n}, z\right)=0
$$

Since $\lim _{m, n \rightarrow \infty} p_{b}\left(x_{n}, x_{m}\right)=0$, from Lemma 1.9

$$
\lim _{n \rightarrow \infty} p_{b}\left(x_{n}, z\right)=\lim _{m, n \rightarrow \infty} p_{b}\left(x_{n}, x_{m}\right)=p_{b}(z, z)=0 .
$$

From the continuity of $f$ we have

$$
\lim _{n \rightarrow \infty} p_{b}\left(x_{n+1}, f z\right)=p_{b}(f z, f z)
$$

and hence we get

$$
p_{b}(z, f z) \leq \lim _{n \rightarrow \infty} s p_{b}\left(z, x_{n+1}\right)+\lim _{n \rightarrow \infty} s p_{b}\left(x_{n+1}, f z\right)=s p_{b}(f z, f z) .
$$

So, we get $p_{b}(z, f z) \leq s p_{b}(f z, f z)$. As $\alpha(z, z) \geq 1$, we have

$$
p_{b}(z, f z) \leq s \alpha(z, z) p_{b}(f z, f z) \leq \psi\left(\max \left\{p_{b}(z, z), p_{b}(z, f z), p_{b}(z, f z), \frac{p_{b}(z, f z)+p_{b}(f z, z)}{2 s}\right\}\right)
$$

Hence, $p_{b}(z, f z) \leq \psi\left(p_{b}(z, f z)\right)$. Thus, $p_{b}(z, f z)=0$, that is, $z=f z$.

In Theorem 2.6, we omit the continuity of the mapping $f$ and we replace $\alpha\left(x_{n}, x\right) \geq 1$ instead of $\alpha(x, x) \geq 1$ and rearrange it as follows.

Theorem 2.7 Let $\left(X, p_{b}\right)$ be a $p_{b}$-complete partial b-metric space and $f$ be an $\alpha$-admissible mapping on $X$ such that

$$
s \alpha(x, y) p_{b}(f x, f y) \leq \psi\left(M_{s}(x, y)\right)
$$

for all $x, y \in X$, where $\psi \in \Psi_{b}$. Assume that the following conditions hold:

(i) there exists $x_{0} \in X$ such that $\alpha\left(x_{0}, f x_{0}\right) \geq 1$;

(ii) if $\left\{x_{n}\right\}$ is a sequence in $X$ such that $\alpha\left(x_{n}, x_{n+1}\right) \geq 1$ for all $n$ and $x_{n} \rightarrow x$ as $n \rightarrow \infty$, then $\alpha\left(x_{n}, x\right) \geq 1$ for all $n \in \mathbb{N} \cup\{0\}$.

Then $f$ has a fixed point. 
Proof Let $x_{0} \in X$ be such that $\alpha\left(x_{0}, f x_{0}\right) \geq 1$ and define a sequence $\left\{x_{n}\right\}$ in $X$ by $x_{n}=$ $f^{n} x_{0}=f x_{n-1}$ for all $n \in \mathbb{N}$. Following the proof of Theorem 2.6, we have $\alpha\left(x_{n}, x_{n+1}\right) \geq 1$ for all $n \in \mathbb{N} \cup\{0\}$ and there exists $z \in X$ such that $x_{n} \rightarrow z$ as $n \rightarrow \infty$ which $p_{b}(z, z)=0$. Hence, from (ii) we deduce that $\alpha\left(x_{n}, z\right) \geq 1$ for all $n \in \mathbb{N} \cup\{0\}$. Therefore, by (2.7), we obtain

$$
s p_{b}\left(f z, x_{n+1}\right) \leq s \alpha\left(x_{n}, z\right) p_{b}\left(f z, f x_{n}\right) \leq \psi\left(M_{s}\left(z, x_{n}\right)\right) .
$$

Here,

$$
\begin{aligned}
M_{s}\left(z, x_{n}\right) & =\max \left\{p_{b}\left(z, x_{n}\right), p_{b}(z, f z), p_{b}\left(x_{n}, f x_{n}\right), \frac{1}{2 s}\left[p_{b}\left(z, f x_{n}\right)+p_{b}\left(x_{n}, f z\right)\right]\right\} \\
& =\max \left\{p_{b}\left(z, x_{n}\right), p_{b}(z, f z), p_{b}\left(x_{n}, x_{n+1}\right), \frac{1}{2 s}\left[p_{b}\left(z, x_{n+1}\right)+p_{b}\left(x_{n}, f z\right)\right]\right\} .
\end{aligned}
$$

Taking the upper limit as $n \rightarrow \infty$ in the above inequality from Lemma 1.13 we obtain

$$
s\left[\frac{1}{s} p_{b}(f z, z)\right] \leq s \limsup _{n} p_{b}\left(f z, f x_{n}\right) \leq \psi\left(\limsup _{n} M_{s}\left(z, x_{n}\right)\right) \leq \psi\left(p_{b}(z, f z)\right),
$$

which implies that $z=f z$.

Definition 2.8 [18] Let $f: X \rightarrow X$ and $\alpha: X \times X \rightarrow \mathbb{R}$. We say that $f$ is a triangular $\alpha$ admissible mapping if

(T1) $\alpha(x, y) \geq 1$ implies $\alpha(f x, f y) \geq 1, x, y \in X$,

(T2) $\left\{\begin{array}{l}\alpha(x, z) \geq 1 \\ \alpha(z, y) \geq 1\end{array}\right.$ implies $\alpha(x, y) \geq 1, x, y, z \in X$.

Example 2.9 [18] Let $X=\mathbb{R}, f x=\sqrt[3]{x}$, and $\alpha(x, y)=e^{x-y}$, then $f$ is a triangular $\alpha$-admissible mapping. Indeed, if $\alpha(x, y)=e^{x-y} \geq 1$, then $x \geq y$ which implies that $f x \geq f y$, that is, $\alpha(f x, f y)=e^{f x-f y} \geq 1$. Also, if $\left\{\begin{array}{l}\alpha(x, z) \geq 1 \\ \alpha(z, y) \geq 1\end{array}\right.$, then $\left\{\begin{array}{l}x-z \geq 0 \\ z-y \geq 0\end{array}\right.$, that is, $x-y \geq 0$ and therefore $\alpha(x, y)=$ $e^{x-y} \geq 1$.

Example 2.10 [18] Let $X=\mathbb{R}, f x=e^{x^{7}}$, and $\alpha(x, y)=\sqrt[5]{x-y}+1$. Hence, $f$ is a triangular $\alpha$-admissible mapping. Indeed, if $\alpha(x, y)=\sqrt[5]{x-y}+1 \geq 1$ then $x \geq y$ which implies that $f x \geq f y$, that is, $\alpha(f x, f y) \geq 1$.

Moreover, if $\left\{\begin{array}{l}\alpha(x, z) \geq 1 \\ \alpha(z, y) \geq 1\end{array}\right.$, then $x-y \geq 0$ and hence $\alpha(x, y) \geq 1$.

Example 2.11 [18] Let $X=[0, \infty), f x=x^{4}+\ln \left(x^{2}+1\right)$, and

$$
\alpha(x, y)=\frac{x^{3}}{1+x^{3}}-\frac{y^{3}}{y^{3}+1}+1
$$

Then $f$ is a triangular $\alpha$-admissible mapping. In fact, if

$$
\alpha(x, y)=\frac{x^{3}}{1+x^{3}}-\frac{y^{3}}{y^{3}+1}+1 \geq 1
$$


then $x \geq y$. Hence, $f x \geq f y$, that is, $\alpha(f x, f y) \geq 1$. Also,

$$
\begin{aligned}
\alpha(x, z)+\alpha(z, y) & =\frac{x^{3}}{1+x^{3}}-\frac{z^{3}}{z^{3}+1}+1+\frac{z^{3}}{1+z^{3}}-\frac{y^{3}}{y^{3}+1}+1 \\
& =\frac{x^{3}}{1+x^{3}}-\frac{y^{3}}{y^{3}+1}+2 \leq 2\left(\frac{x^{3}}{1+x^{3}}-\frac{y^{3}}{y^{3}+1}+1\right)=2 \alpha(x, y) .
\end{aligned}
$$

Thus, $\alpha(x, z)+\alpha(z, y) \leq 2 \alpha(x, y)$. Now, if $\left\{\begin{array}{l}\alpha(x, z) \geq 1 \\ \alpha(z, y) \geq 1\end{array}\right.$, then $\alpha(x, y) \geq 1$.

Example 2.12 [18] Let $X=\mathbb{R}, f x=x^{3}+\sqrt[7]{x}$, and $\alpha(x, y)=x^{5}-y^{5}+1$. Then $f$ is a triangular $\alpha$-admissible mapping.

Lemma 2.13 [18] Let $f$ be a triangular $\alpha$-admissible mapping. Assume that there exists $x_{0} \in X$ such that $\alpha\left(x_{0}, f x_{0}\right) \geq 1$. Define the sequence $\left\{x_{n}\right\}$ by $x_{n}=f^{n} x_{0}$. Then

$$
\alpha\left(x_{m}, x_{n}\right) \geq 1 \text { for all } m, n \in \mathbb{N} \text { with } m<n
$$

A mapping $\psi:[0, \infty) \rightarrow[0, \infty)$ is called a comparison function if it increasing and $\psi^{n}(t) \rightarrow 0$, as $n \rightarrow \infty$ for any $t \in[0, \infty)$.

Lemma 2.14 (Berinde [15], Rus [19]) If $\psi:[0, \infty) \rightarrow[0, \infty)$ is a comparison function, then:

(1) each iterate $\psi^{k}$ of $\psi, k \geq 1$, is also a comparison function;

(2) $\psi$ is continuous at 0 ;

(3) $\psi(t)<t$, for any $t>0$.

Denote by $\Psi$ the family of all continuous comparison functions $\psi:[0, \infty) \rightarrow[0, \infty)$.

In the sequel, $\psi \in \Psi, \alpha: X \times X \rightarrow[0, \infty)$ is a function and

$$
M_{s}(x, y)=\max \left\{p_{b}(x, y), p_{b}(x, f x), p_{b}(y, f y), \frac{1}{2 s}\left[p_{b}(x, f y)+p_{b}(y, f x)\right]\right\} .
$$

Theorem 2.15 Let $\left(X, p_{b}\right)$ be a $p_{b}$-complete partial b-metric space, $f$ be a continuous triangular $\alpha$-admissible mapping on $X$, there exists $x_{0} \in X$ such that $\alpha\left(x_{0}, f x_{0}\right) \geq 1$ and if any sequence $\left\{x_{n}\right\}$ in $X p_{b}$-converges to a point $x$, where $\alpha\left(x_{n}, x_{n+1}\right) \geq 1$ for all $n$, then we have $\alpha(x, x) \geq 1$. Assume that

$$
s \alpha(x, y) p_{b}(f x, f y) \leq \psi\left(M_{s}(x, y)\right)
$$

for all $x, y \in X$. Then $f$ has a fixed point.

Proof Let $x_{0} \in X$ be such that $\alpha\left(x_{0}, f x_{0}\right) \geq 1$. Define a sequence $\left\{x_{n}\right\}$ by $x_{n}=f^{n} x_{0}$ for all $n \in \mathbb{N}$. Since $f$ is an $\alpha$-admissible mapping and $\alpha\left(x_{0}, x_{1}\right)=\alpha\left(x_{0}, f x_{0}\right) \geq 1$, we deduce that $\alpha\left(x_{1}, x_{2}\right)=\alpha\left(f x_{0}, f x_{1}\right) \geq 1$. Continuing this process, we get $\alpha\left(x_{n}, x_{n+1}\right) \geq 1$ for all $n \in \mathbb{N} \cup\{0\}$.

Now, we will finish the proof in the following steps.

Step I. We will prove that

$$
\lim _{n \rightarrow \infty} p_{b}\left(x_{n}, x_{n+1}\right)=0
$$


First, we prove that

$$
p_{b}\left(x_{n}, x_{n+1}\right) \leq \psi\left(p_{b}\left(x_{n-1}, x_{n}\right)\right)
$$

for each $n=1,2,3, \ldots$.

If $x_{n}=x_{n+1}$, for some $n \in \mathbb{N}$, then $x_{n}=f x_{n}$. Thus, $x_{n}$ is a fixed point of $f$. Therefore, we assume that $x_{n} \neq x_{n+1}$, for all $n \in \mathbb{N}$.

Using condition (2.8) as $\alpha\left(x_{n-1}, x_{n}\right) \geq 1$ for all $n \in \mathbb{N} \cup\{0\}$, we obtain

$$
s p_{b}\left(x_{n}, x_{n+1}\right) \leq s \alpha\left(x_{n-1}, x_{n}\right) p_{b}\left(f x_{n-1}, f x_{n}\right) \leq \psi\left(M_{s}\left(x_{n-1}, x_{n}\right)\right) .
$$

Here,

$$
\begin{aligned}
& M_{s}\left(x_{n-1}, x_{n}\right) \\
& \quad=\max \left\{p_{b}\left(x_{n-1}, x_{n}\right), p_{b}\left(x_{n-1}, f x_{n-1}\right), p_{b}\left(x_{n}, f x_{n}\right), \frac{1}{2 s}\left[p_{b}\left(x_{n-1}, f x_{n}\right)+p_{b}\left(x_{n}, f x_{n-1}\right)\right]\right\} \\
& \quad=\max \left\{p_{b}\left(x_{n-1}, x_{n}\right), p_{b}\left(x_{n-1}, x_{n}\right), p_{b}\left(x_{n}, x_{n+1}\right), \frac{1}{2 s}\left[p_{b}\left(x_{n-1}, x_{n+1}\right)+p_{b}\left(x_{n}, x_{n}\right)\right]\right\} \\
& \quad \leq \max \left\{p_{b}\left(x_{n-1}, x_{n}\right), p_{b}\left(x_{n}, x_{n+1}\right)\right\} .
\end{aligned}
$$

If $p_{b}\left(x_{n}, x_{n+1}\right) \geq p_{b}\left(x_{n-1}, x_{n}\right)$, then

$$
M_{s}\left(x_{n-1}, x_{n}\right) \leq p_{b}\left(x_{n}, x_{n+1}\right)
$$

which yields

$$
s p_{b}\left(x_{n}, x_{n+1}\right) \leq \psi\left(p_{b}\left(x_{n}, x_{n+1}\right)\right)<p_{b}\left(x_{n}, x_{n+1}\right),
$$

a contradiction.

Hence,

$$
p_{b}\left(x_{n}, x_{n+1}\right) \leq \psi\left(p_{b}\left(x_{n-1}, x_{n}\right)\right) .
$$

So (2.9) holds.

By induction, we get

$$
p_{b}\left(x_{n}, x_{n+1}\right) \leq \psi\left(p_{b}\left(x_{n-1}, x_{n}\right)\right) \leq \psi^{2}\left(p_{b}\left(x_{n-2}, x_{n-1}\right)\right) \leq \cdots \leq \psi^{n}\left(p_{b}\left(x_{0}, x_{1}\right)\right) .
$$

As $\psi \in \Psi$, we conclude that

$$
\lim _{n \rightarrow \infty} p_{b}\left(x_{n}, x_{n+1}\right)=0 \text {. }
$$

So by $\left(p_{b 2}\right)$ we get

$$
\lim _{n \rightarrow \infty} p_{b}\left(x_{n}, x_{n}\right)=0 .
$$


Step II. We will show that $\left\{x_{n}\right\}$ is a $p_{b}$-Cauchy sequence in $X$. For this, we have to show that $\left\{x_{n}\right\}$ is a $b$-Cauchy sequence in $\left(X, d_{p_{b}}\right)$ (see Lemma 1.9). Suppose the contrary; that is, $\left\{x_{n}\right\}$ is not a $b$-Cauchy sequence. Then there exists $\varepsilon>0$ for which we can find two subsequences $\left\{x_{m_{i}}\right\}$ and $\left\{x_{n_{i}}\right\}$ of $\left\{x_{n}\right\}$ such that $n_{i}$ is the smallest index for which

$$
n_{i}>m_{i}>i \text { and } d_{p_{b}}\left(x_{m_{i}}, x_{n_{i}}\right) \geq \varepsilon
$$

This means that

$$
d_{p_{b}}\left(x_{m_{i}}, x_{n_{i}-1}\right)<\varepsilon
$$

From (2.13) and using the triangular inequality, we get

$$
\varepsilon \leq d_{p_{b}}\left(x_{m_{i}}, x_{n_{i}}\right) \leq s d_{p_{b}}\left(x_{m_{i}}, x_{n_{i}-1}\right)+s d_{p_{b}}\left(x_{n_{i}-1}, x_{n_{i}}\right) .
$$

Using (2.11), (2.12), and from the definition of $d_{p_{b}}$ and (2.14), and taking the upper limit as $i \rightarrow \infty$, we get

$$
\frac{\varepsilon}{s} \leq \limsup _{i \rightarrow \infty} d_{p_{b}}\left(x_{m_{i}}, x_{n_{i}-1}\right) \leq \varepsilon
$$

Also,

$$
\varepsilon \leq \liminf _{i \rightarrow \infty} d_{p_{b}}\left(x_{m_{i}}, x_{n_{i}}\right) \leq \limsup _{i \rightarrow \infty} d_{p_{b}}\left(x_{m_{i}}, x_{n_{i}}\right) \leq s \varepsilon .
$$

Further,

$$
\frac{\varepsilon}{s} \leq \limsup _{i \rightarrow \infty} d_{p_{b}}\left(x_{m_{i}+1}, x_{n_{i}}\right) \leq s^{2} \varepsilon
$$

and

$$
\limsup _{i \rightarrow \infty} d_{p_{b}}\left(x_{m_{i}+1}, x_{n_{i}-1}\right) \leq s \varepsilon .
$$

On the other hand, by the definition of $d_{p_{b}}$ and (2.12)

$$
\limsup _{i \rightarrow \infty} d_{p_{b}}\left(x_{m_{i}}, x_{n_{i}-1}\right)=2 \limsup _{i \rightarrow \infty} p_{b}\left(x_{m_{i}}, x_{n_{i}-1}\right) .
$$

Hence, by (2.15),

$$
\frac{\varepsilon}{2 s} \leq \limsup _{i \rightarrow \infty} p_{b}\left(x_{m_{i}}, x_{n_{i}-1}\right) \leq \frac{\varepsilon}{2} .
$$

Similarly,

$$
\begin{aligned}
& \frac{\varepsilon}{2} \leq \liminf _{i \rightarrow \infty} p_{b}\left(x_{m_{i}}, x_{n_{i}}\right) \leq \limsup _{i \rightarrow \infty} p_{b}\left(x_{m_{i}}, x_{n_{i}}\right) \leq \frac{s \varepsilon}{2}, \\
& \frac{\varepsilon}{2 s} \leq \limsup _{i \rightarrow \infty} p_{b}\left(x_{m_{i}+1}, x_{n_{i}}\right) \leq \frac{s^{2} \varepsilon}{2},
\end{aligned}
$$


and

$$
\limsup _{i \rightarrow \infty} p_{b}\left(x_{m_{i}+1}, x_{n_{i}-1}\right) \leq \frac{s \varepsilon}{2} .
$$

From (2.8) and Lemma 2.13 as $\alpha\left(x_{m_{i}}, x_{n_{i}-1}\right) \geq 1$, we have

$$
s p_{b}\left(x_{m_{i}+1}, x_{n_{i}}\right) \leq s \alpha\left(x_{m_{i}}, x_{n_{i}-1}\right) p_{b}\left(f x_{m_{i}}, f x_{n_{i}-1}\right) \leq \psi\left(M_{s}\left(x_{m_{i}}, x_{n_{i}-1}\right)\right),
$$

where

$$
\begin{aligned}
M_{s}\left(x_{m_{i}}, x_{n_{i}-1}\right)= & \max \left\{p_{b}\left(x_{m_{i}}, x_{n_{i}-1}\right), p_{b}\left(x_{m_{i}}, f x_{m_{i}}\right), p_{b}\left(x_{n_{i}-1}, f x_{n_{i}-1}\right),\right. \\
& \left.\frac{p_{b}\left(x_{m_{i}}, f x_{n_{i}-1}\right)+p_{b}\left(f x_{m_{i}}, x_{n_{i}-1}\right)}{2 s}\right\} \\
= & \max \left\{p_{b}\left(x_{m_{i}}, x_{n_{i}-1}\right), p_{b}\left(x_{m_{i}}, x_{m_{i}+1}\right), p_{b}\left(x_{n_{i}-1}, x_{n_{i}}\right),\right. \\
& \left.\frac{p_{b}\left(x_{m_{i}}, x_{n_{i}}\right)+p_{b}\left(x_{m_{i}+1}, x_{n_{i}-1}\right)}{2 s}\right\} .
\end{aligned}
$$

Taking the upper limit as $i \rightarrow \infty$ in (2.24) and using (2.11), (2.19), (2.20), and (2.22), we get

$$
\begin{aligned}
\limsup _{i \rightarrow \infty} M_{s}\left(x_{m_{i}}, x_{n_{i}-1}\right)= & \max \left\{\limsup _{i \rightarrow \infty} p_{b}\left(x_{m_{i}}, x_{n_{i}-1}\right), 0,0\right. \\
& \left.\frac{\limsup _{i \rightarrow \infty} p_{b}\left(x_{m_{i}}, x_{n_{i}}\right)+\limsup \sup _{i \rightarrow \infty} p_{b}\left(x_{m_{i}+1}, x_{n_{i}-1}\right)}{2 s}\right\} \\
\leq & \max \left\{\frac{\varepsilon}{2}, \frac{\frac{\varepsilon s+\varepsilon s}{2}}{2 s}\right\}=\frac{\varepsilon}{2} .
\end{aligned}
$$

Now, taking the upper limit as $i \rightarrow \infty$ in (2.23) and using (2.21) and (2.25), we have

$$
s \frac{\varepsilon}{2 s} \leq s \limsup _{i \rightarrow \infty} p_{b}\left(x_{m_{i}+1}, x_{n_{i}}\right) \leq \psi\left(\limsup _{i \rightarrow \infty} M_{s}\left(x_{m_{i}}, x_{n_{i}-1}\right)\right)<\frac{\varepsilon}{2},
$$

a contradiction.

Step III. There exists $z$ such that $f z=z$.

Since $\left\{x_{n}\right\}$ is a $p_{b}$-Cauchy sequence in the $p_{b}$-complete partial $b$-metric space $X$, from Lemma $1.9,\left\{x_{n}\right\}$ is a $b$-Cauchy sequence in the $b$-metric space $\left(X, d_{p_{b}}\right) \cdot p_{b}$-Completeness of $\left(X, p_{b}\right)$ shows that $\left(X, d_{p_{b}}\right)$ is also $b$-complete. Then there exists $z \in X$ such that

$$
\lim _{n \rightarrow \infty} d_{p_{b}}\left(x_{n}, z\right)=0
$$

Since $\lim _{m, n \rightarrow \infty} d_{p_{b}}\left(x_{n}, x_{m}\right)=0$, from the definition of $d_{p_{b}}$ and (2.12), we get

$$
\lim _{m, n \rightarrow \infty} p_{b}\left(x_{n}, x_{m}\right)=0
$$

Again, from Lemma 1.9,

$$
\lim _{n \rightarrow \infty} p_{b}\left(z, x_{n}\right)=\lim _{m, n \rightarrow \infty} p_{b}\left(x_{n}, x_{m}\right)=p_{b}(z, z)=0
$$


From the continuity of $f$ we have

$$
\lim _{n \rightarrow \infty} p_{b}\left(x_{n+1}, f z\right)=p_{b}(f z, f z)
$$

and hence we get

$$
p_{b}(z, f z) \leq \lim _{n \rightarrow \infty} s p_{b}\left(z, x_{n+1}\right)+\lim _{n \rightarrow \infty} s p_{b}\left(x_{n+1}, f z\right)=s p_{b}(f z, f z) .
$$

So, we get $p_{b}(z, f z) \leq s p_{b}(f z, f z)$. As $\alpha(z, z) \geq 1$, we have

$$
\begin{aligned}
p_{b}(z, f z) & \leq s \alpha(z, z) p_{b}(f z, f z) \\
& \leq \psi\left(\max \left\{p_{b}(z, z), p_{b}(z, f z), p_{b}(z, f z), \frac{p_{b}(z, f z)+p_{b}(f z, z)}{2 s}\right\}\right) .
\end{aligned}
$$

Hence, $p_{b}(z, f z) \leq \psi\left(p_{b}(z, f z)\right)$. Thus, $p_{b}(z, f z)=0$, that is, $z=f z$.

If in Theorem 2.15 we take $\alpha(x, y)=1$ then we deduce the following corollary.

Corollary 2.16 Let $\left(X, p_{b}\right)$ be a $p_{b}$-complete partial b-metric space and $f$ be a continuous mapping on $X$. Assume that

$$
s p_{b}(f x, f y) \leq \psi\left(M_{s}(x, y)\right)
$$

for all $x, y \in X$. Then $f$ has a fixed point.

In Theorem 2.15, we omit the continuity of the mapping $f$ and we replace $\alpha\left(x_{n}, x\right) \geq 1$ instead of $\alpha(x, x) \geq 1$ and rearrange it as follows.

Theorem 2.17 Let $\left(X, p_{b}\right)$ be a $p_{b}$-complete partial b-metric space and $f$ be a triangular $\alpha$-admissible mapping on $X$ such that

$$
s \alpha(x, y) p_{b}(f x, f y) \leq \psi\left(M_{s}(x, y)\right)
$$

for all $x, y \in X$, where $\psi \in \Psi$. Assume that the following conditions hold:

(i) there exists $x_{0} \in X$ such that $\alpha\left(x_{0}, f x_{0}\right) \geq 1$;

(ii) if $\left\{x_{n}\right\}$ is a sequence in $X$ such that $\alpha\left(x_{n}, x_{n+1}\right) \geq 1$ for all $n$ and $x_{n} \rightarrow x$ as $n \rightarrow \infty$, then $\alpha\left(x_{n}, x\right) \geq 1$ for all $n \in \mathbb{N} \cup\{0\}$.

Then $f$ has a fixed point.

Proof Let $x_{0} \in X$ be such that $\alpha\left(x_{0}, f x_{0}\right) \geq 1$ and define a sequence $\left\{x_{n}\right\}$ in $X$ by $x_{n}=f^{n} x_{0}=$ $f x_{n-1}$ for all $n \in \mathbb{N}$. Following the proof of Theorem 2.15, we have $\alpha\left(x_{n}, x_{n+1}\right) \geq 1$ for all $n \in \mathbb{N} \cup\{0\}$ and there exists $z \in X$ such that $x_{n} \rightarrow z$ as $n \rightarrow \infty$ which $p_{b}(z, z)=0$. Hence, from (ii) we deduce that $\alpha\left(x_{n}, z\right) \geq 1$ for all $n \in \mathbb{N} \cup\{0\}$. Therefore, by (2.29), we obtain

$$
s p_{b}\left(f z, x_{n+1}\right) \leq s \alpha\left(x_{n}, z\right) p_{b}\left(f z, f x_{n}\right) \leq \psi\left(M_{s}\left(z, x_{n}\right)\right) .
$$


Here,

$$
\begin{aligned}
M_{s}\left(z, x_{n}\right) & =\max \left\{p_{b}\left(z, x_{n}\right), p_{b}(z, f z), p_{b}\left(x_{n}, f x_{n}\right), \frac{1}{2 s}\left[p_{b}\left(z, f x_{n}\right)+p_{b}\left(x_{n}, f z\right)\right]\right\} \\
& =\max \left\{p_{b}\left(z, x_{n}\right), p_{b}(z, f z), p_{b}\left(x_{n}, x_{n+1}\right), \frac{1}{2 s}\left[p_{b}\left(z, x_{n+1}\right)+p_{b}\left(x_{n}, f z\right)\right]\right\} .
\end{aligned}
$$

Taking the upper limit as $n \rightarrow \infty$ in the above inequality from Lemma 1.13 we obtain

$$
s\left[\frac{1}{s} p_{b}(f z, z)\right] \leq s \limsup _{n} p_{b}\left(f z, f x_{n}\right) \leq \psi\left(\limsup _{n} M_{s}\left(z, x_{n}\right)\right) \leq \psi\left(p_{b}(z, f z)\right),
$$

which implies that $z=f z$.

Example 2.18 Let $X=[0,1]$ and $p_{b}(x, y)=|x-y|^{2}$ be a $p_{b}$-metric on $X$. Define $f: X \rightarrow X$ by $f x=\ln \left(\frac{x}{4}+1\right)$ and $\alpha: X \times X \rightarrow[0, \infty)$ by

$$
\alpha(x, y)= \begin{cases}1, & \text { if }(x, y) \in\left[0, \frac{1}{4}\right] \times\left[0, \frac{1}{4}\right] \\ 0, & \text { otherwise }\end{cases}
$$

and $\psi(t)=\frac{t}{8}$ for all $t \in[0, \infty)$. Now, we prove that all the hypotheses of Theorem 2.17 are satisfied and hence $f$ has a fixed point.

First, we see that $\left(X, p_{b}\right)$ is a $p_{b}$-complete partial $b$-metric space. Let $x, y \in X$. If $\alpha(x, y) \geq$ 1 , then $x, y \in\left[0, \frac{1}{4}\right]$. On the other hand, for all $x \in[0,1]$, we have $f x \leq \frac{x}{4} \leq \frac{1}{4}$ and hence $\alpha(f x, f y)=1$. This implies that $f$ is a triangular $\alpha$-admissible mapping on $X$. Obviously, $\alpha(0, f 0)=1$.

Now, if $\left\{x_{n}\right\}$ is a sequence in $X$ such that $\alpha\left(x_{n}, x_{n+1}\right)=1$ for all $n \in \mathbb{N} \cup\{0\}$ and $x_{n} \rightarrow x$ as $n \rightarrow \infty$, it is easy to see that $\alpha\left(x_{n}, x\right)=1$.

Using the Mean Value Theorem for the function $f x=\ln \left(\frac{x}{4}+1\right)$ for any $x, y \in X$, we have

$$
\begin{aligned}
s \alpha(x, y) p_{b}(f x, f y) & \leq s p_{b}(f x, f y)=2|f x-f y|^{2} \\
& =2\left|\ln \left(\frac{x}{4}+1\right)-\ln \left(\frac{y}{4}+1\right)\right|^{2} \\
& \leq \frac{1}{8}|x-y|^{2}=\psi\left(p_{b}(x, y)\right) \leq \psi\left(M_{s}(x, y)\right) .
\end{aligned}
$$

Thus, all the conditions of Theorem 2.17 are satisfied and therefore $f$ has a fixed point $(z=0)$.

\section{Common fixed points of generalized almost cyclic weakly $(\psi, \varphi, L, A, B)$-contractive mappings}

In this section, we consider the notion of ordered cyclic weakly $(\psi, \varphi, L, A, B)$-contractions in the setup of ordered partial $b$-metric spaces and then obtain some common fixed point theorems for these cyclic contractions in the setup of complete ordered partial $b$-metric spaces. Our results extend some fixed point theorems from the framework of ordered metric spaces and ordered $b$-metric spaces, in particular Theorems 1.20 and 1.21. 
We shall call an ordered partial $b$-metric space $\left(X, \preceq, p_{b}\right)$ regular if for any nondecreasing sequence $\left\{x_{n}\right\}$ in $X$ such that $x_{n} \rightarrow x \in X$, as $n \rightarrow \infty$, one has $x_{n} \preceq x$, for all $n \in \mathbb{N}$.

Definition 3.1 Let $\left(X, \preceq, p_{b}\right)$ be an ordered partial $b$-metric space, let $f, g: X \rightarrow X$ be two mappings, and let $A$ and $B$ be nonempty closed subsets of $X$. The pair $(f, g)$ is called an ordered cyclic almost generalized weakly $(\psi, \varphi, L, A, B)$-contraction if

(1) $X=A \cup B$ is a cyclic representation of $X$ w.r.t. the pair $(f, g)$; that is, $f A \subseteq B$ and $g B \subseteq A$

(2) there exist two altering distance functions $\psi, \varphi$ and a constant $L \geq 0$, such that for arbitrary comparable elements $x, y \in X$ with $x \in A$ and $y \in B$, we have

$$
\psi\left(s^{2} p_{b}(f x, g y)\right) \leq \psi\left(M_{s}(x, y)\right)-\varphi\left(M_{s}(x, y)\right)+L \psi(N(x, y)),
$$

where

$$
M_{s}(x, y)=\max \left\{p_{b}(x, y), p_{b}(x, f x), p_{b}(y, g y), \frac{p_{b}(x, g y)+p_{b}(y, f x)}{2 s}\right\}
$$

and

$$
N(x, y)=\min \left\{d_{p_{b}}(x, f x), d_{p_{b}}(x, g y), d_{p_{b}}(y, f x), d_{p_{b}}(y, g y)\right\} .
$$

Theorem 3.2 Let $\left(X, \preceq, p_{b}\right)$ be a $p_{b}$-complete ordered partial b-metric space and $A$ and $B$ be two nonempty closed subsets of $X$. Let $f, g: X \rightarrow X$ be two $(A, B)$-weakly increasing mappings with respect to $\preceq$. Suppose that the pair $(f, g)$ is an ordered cyclic almost generalized weakly $(\psi, \varphi, L, A, B)$-contraction. Then $f$ and $g$ have a common fixed point $z \in A \cap B$.

Proof First, note that $u \in A \cap B$ is a fixed point of $f$ if and only if $u$ is a fixed point of $g$. Indeed, suppose that $u$ is a fixed point of $f$. As $u \preceq u$ and $u \in A \cap B$, by (3.1), we have

$$
\begin{aligned}
\psi\left(s^{2} p_{b}(u, g u)\right)= & \psi\left(s^{2} p_{b}(f u, g u)\right) \\
\leq & \psi\left(\max \left\{p_{b}(u, u), p_{b}(u, f u), p_{b}(u, g u), \frac{1}{2 s}\left(p_{b}(u, g u)+p_{b}(u, f u)\right)\right\}\right) \\
& -\varphi\left(\max \left\{p_{b}(u, u), p_{b}(u, f u), p_{b}(u, g u), \frac{1}{2 s}\left(p_{b}(u, g u)+p_{b}(u, f u)\right)\right\}\right) \\
& +L \min \left\{d_{p_{b}}(u, g u), d_{p_{b}}(u, f u)\right\} \\
= & \psi\left(p_{b}(u, g u)\right)-\varphi\left(p_{b}(u, g u)\right) \\
\leq & \psi\left(s^{2} p_{b}(u, g u)\right)-\varphi\left(p_{b}(u, g u)\right) .
\end{aligned}
$$

It follows that $\varphi\left(p_{b}(u, g u)\right)=0$. Therefore, $p_{b}(u, g u)=0$ and hence $g u=u$. Similarly, we can show that if $u$ is a fixed point of $g$, then $u$ is a fixed point of $f$.

Let $x_{0} \in A$ and let $x_{1}=f x_{0}$. Since $f A \subseteq B$, we have $x_{1} \in B$. Also, let $x_{2}=g x_{1}$. Since $g B \subseteq A$, we have $x_{2} \in A$. Continuing this process, we can construct a sequence $\left\{x_{n}\right\}$ in $\mathrm{X}$ such that 
$x_{2 n+1}=f x_{2 n}, x_{2 n+2}=g x_{2 n+1}, x_{2 n} \in A$ and $x_{2 n+1} \in B$. Since $f$ and $g$ are $(A, B)$-weakly increasing, we have

$$
x_{1}=f x_{0} \preceq g f x_{0}=x_{2}=g x_{1} \preceq f g x_{1}=x_{3} \preceq \cdots \preceq x_{2 n+1}=f x_{2 n} \preceq g f x_{2 n}=x_{2 n+2} \preceq \cdots .
$$

If $x_{2 n}=x_{2 n+1}$, for some $n \in \mathbb{N}$, then $x_{2 n}=f x_{2 n}$. Thus $x_{2 n}$ is a fixed point of $f$. By the first part of the proof, we conclude that $x_{2 n}$ is also a fixed point of $g$. Similarly, if $x_{2 n+1}=x_{2 n+2}$, for some $n \in \mathbb{N}$, then $x_{2 n+1}=g x_{2 n+1}$. Thus, $x_{2 n+1}$ is a fixed point of $g$. By the first part of the proof, we conclude that $x_{2 n+1}$ is also a fixed point of $f$. Therefore, we assume that $x_{n} \neq x_{n+1}$, for all $n \in \mathbb{N}$. Now, we complete the proof in the following steps.

Step 1. We will prove that

$$
\lim _{n \rightarrow \infty} p_{b}\left(x_{n}, x_{n+1}\right)=0
$$

As $x_{2 n}$ and $x_{2 n+1}$ are comparable and $x_{2 n} \in A$ and $x_{2 n+1} \in B$, by (3.1), we have

$$
\begin{aligned}
\psi\left(p_{b}\left(x_{2 n+1}, x_{2 n+2}\right)\right) & \leq \psi\left(s^{2} p_{b}\left(x_{2 n+1}, x_{2 n+2}\right)\right) \\
& =\psi\left(s^{2} p_{b}\left(f x_{2 n}, g x_{2 n+1}\right)\right) \\
& \leq \psi\left(M_{s}\left(x_{2 n}, x_{2 n+1}\right)\right)-\varphi\left(M_{s}\left(x_{2 n}, x_{2 n+1}\right)\right)+L \psi\left(N\left(x_{2 n}, x_{2 n+1}\right)\right),
\end{aligned}
$$

where

$$
\begin{aligned}
M_{s}\left(x_{2 n}, x_{2 n+1}\right)= & \max \left\{p_{b}\left(x_{2 n}, x_{2 n+1}\right), p_{b}\left(x_{2 n}, f x_{2 n}\right), p_{b}\left(x_{2 n+1}, g x_{2 n+1}\right),\right. \\
& \left.\frac{p_{b}\left(f x_{2 n}, x_{2 n+1}\right)+p_{b}\left(x_{2 n}, g x_{2 n+1}\right)}{2 s}\right\} \\
= & \max \left\{p_{b}\left(x_{2 n}, x_{2 n+1}\right), p_{b}\left(x_{2 n+1}, x_{2 n+2}\right), \frac{p_{b}\left(x_{2 n+1}, x_{2 n+1}\right)+p_{b}\left(x_{2 n}, x_{2 n+2}\right)}{2 s}\right\} \\
\leq & \max \left\{p_{b}\left(x_{2 n}, x_{2 n+1}\right), p_{b}\left(x_{2 n+1}, x_{2 n+2}\right),\right. \\
& \left.\frac{s\left[p_{b}\left(x_{2 n}, x_{2 n+1}\right)+p_{b}\left(x_{2 n+1}, x_{2 n+2}\right)\right]}{2 s}\right\} \\
= & \max \left\{p_{b}\left(x_{2 n}, x_{2 n+1}\right), p_{b}\left(x_{2 n+1}, x_{2 n+2}\right)\right\}
\end{aligned}
$$

and

$$
\begin{aligned}
N\left(x_{2 n}, x_{2 n+1}\right) & =\min \left\{d_{p_{b}}\left(x_{2 n}, f x_{2 n}\right), d_{p_{b}}\left(x_{2 n}, g x_{2 n+1}\right), d_{p_{b}}\left(x_{2 n+1}, f x_{2 n}\right), d_{p_{b}}\left(x_{2 n+1}, g x_{2 n+1}\right)\right\} \\
& =\min \left\{d_{p_{b}}\left(x_{2 n}, x_{2 n+1}\right), d_{p_{b}}\left(x_{2 n}, x_{2 n+2}\right), d_{p_{b}}\left(x_{2 n+1}, x_{2 n+1}\right), d_{p_{b}}\left(x_{2 n+1}, x_{2 n+2}\right)\right\} \\
& =0 .
\end{aligned}
$$

Hence, we have

$$
\begin{aligned}
\psi\left(p_{b}\left(x_{2 n+1}, x_{2 n+2}\right)\right) \leq & \psi\left(\max \left\{p_{b}\left(x_{2 n}, x_{2 n+1}\right), p_{b}\left(x_{2 n+1}, x_{2 n+2}\right)\right\}\right) \\
& -\varphi\left(\max \left\{p_{b}\left(x_{2 n}, x_{2 n+1}\right), p_{b}\left(x_{2 n+1}, x_{2 n+2}\right)\right\}\right) .
\end{aligned}
$$


If

$$
\max \left\{p_{b}\left(x_{2 n}, x_{2 n+1}\right), p_{b}\left(x_{2 n+1}, x_{2 n+2}\right)\right\}=p_{b}\left(x_{2 n+1}, x_{2 n+2}\right),
$$

then (3.4) becomes

$$
\begin{aligned}
\psi\left(p_{b}\left(x_{2 n+1}, x_{2 n+2}\right)\right) & \leq \psi\left(p_{b}\left(x_{2 n+1}, x_{2 n+2}\right)\right)-\varphi\left(p_{b}\left(x_{2 n+1}, x_{2 n+2}\right)\right) \\
& <\psi\left(p_{b}\left(x_{2 n+1}, x_{2 n+2}\right)\right)
\end{aligned}
$$

which gives a contradiction. So,

$$
\max \left\{p_{b}\left(x_{2 n}, x_{2 n+1}\right), p_{b}\left(x_{2 n+1}, x_{2 n+2}\right)\right\}=p_{b}\left(x_{2 n}, x_{2 n+1}\right)
$$

and hence (3.4) becomes

$$
\begin{aligned}
\psi\left(p_{b}\left(x_{2 n+1}, x_{2 n+2}\right)\right) & \leq \psi\left(p_{b}\left(x_{2 n}, x_{2 n+1}\right)\right)-\varphi\left(p_{b}\left(x_{2 n}, x_{2 n+1}\right)\right) \\
& <\psi\left(p_{b}\left(x_{2 n}, x_{2 n+1}\right)\right)
\end{aligned}
$$

Similarly, we can show that

$$
\psi\left(p_{b}\left(x_{2 n+1}, x_{2 n}\right)\right)<\psi\left(p_{b}\left(x_{2 n}, x_{2 n-1}\right)\right) .
$$

By (3.5) and (3.6), we see that $\left\{d\left(x_{n}, x_{n+1}\right): n \in \mathbb{N}\right\}$ is a nonincreasing sequence of positive numbers. Hence, there is $r \geq 0$ such that

$$
\lim _{n \rightarrow \infty} p_{b}\left(x_{n}, x_{n+1}\right)=r .
$$

Letting $n \rightarrow \infty$ in (3.5), we get

$$
\psi(r) \leq \psi(r)-\varphi(r)
$$

which implies that $\varphi(r)=0$ and hence $r=0$. So, we have

$$
\lim _{n \rightarrow \infty} p_{b}\left(x_{n}, x_{n+1}\right)=0 \text {. }
$$

Step 2. We will prove that $\left\{x_{n}\right\}$ is a $p_{b}$-Cauchy sequence. Because of (3.7), it is sufficient to show that $\left\{x_{2 n}\right\}$ is a $p_{b}$-Cauchy sequence. By Lemma 1.9, we should show that $\left\{x_{2 n}\right\}$ is $b$-Cauchy in $\left(X, d_{p_{b}}\right)$. Suppose the contrary, i.e., that $\left\{x_{2 n}\right\}$ is not a $b$-Cauchy sequence in $\left(X, d_{p_{b}}\right)$. Then there exists $\varepsilon>0$ for which we can find two subsequences $\left\{x_{2 m_{i}}\right\}$ and $\left\{x_{2 n_{i}}\right\}$ of $\left\{x_{2 n}\right\}$ such that $n_{i}$ is the smallest index for which

$$
n_{i}>m_{i}>i \text { and } d_{p_{b}}\left(x_{2 m_{i}}, x_{2 n_{i}}\right) \geq \varepsilon \text {. }
$$

This means that

$$
d_{p_{b}}\left(x_{2 m_{i}}, x_{2 n_{i}-2}\right)<\varepsilon \text {. }
$$


From (3.8) and using the triangular inequality, we get

$$
\varepsilon \leq d_{p_{b}}\left(x_{2 m_{i}}, x_{2 n_{i}}\right) \leq s d_{p_{b}}\left(x_{2 m_{i}}, x_{2 m_{i}+1}\right)+s d_{p_{b}}\left(x_{2 m_{i}+1}, x_{2 n_{i}}\right) .
$$

Using (3.7) and from the definition of $d_{p_{b}}$ and taking the upper limit as $i \rightarrow \infty$, we get

$$
\frac{\varepsilon}{s} \leq \limsup _{i \rightarrow \infty} d_{p_{b}}\left(x_{2 m_{i}+1}, x_{2 n_{i}}\right)
$$

On the other hand, we have

$$
d_{p_{b}}\left(x_{2 m_{i}}, x_{2 n_{i}-1}\right) \leq s d_{p_{b}}\left(x_{2 m_{i}}, x_{2 n_{i}-2}\right)+s d_{p_{b}}\left(x_{2 n_{i}-2}, x_{2 n_{i}-1}\right) .
$$

Using (3.7), (3.9), and taking the upper limit as $i \rightarrow \infty$, we get

$$
\limsup _{i \rightarrow \infty} d_{p_{b}}\left(x_{2 m_{i}}, x_{2 n_{i}-1}\right) \leq \varepsilon s
$$

Again, using the triangular inequality, we have

$$
\begin{aligned}
d_{p_{b}}\left(x_{2 m_{i}}, x_{2 n_{i}}\right) & \leq s d_{p_{b}}\left(x_{2 m_{i}}, x_{2 n_{i}-2}\right)+s d_{p_{b}}\left(x_{2 n_{i}-2}, x_{2 n_{i}}\right) \\
& \leq s d_{p_{b}}\left(x_{2 m_{i}}, x_{2 n_{i}-2}\right)+s^{2} d_{p_{b}}\left(x_{2 n_{i}-2}, x_{2 n_{i}-1}\right)+s^{2} d_{p_{b}}\left(x_{2 n_{i}-1}, x_{2 n_{i}}\right)
\end{aligned}
$$

and

$$
d_{p_{b}}\left(x_{2 m_{i}+1}, x_{2 n_{i}-1}\right) \leq s d_{p_{b}}\left(x_{2 m_{i}+1}, x_{2 m_{i}}\right)+s d_{p_{b}}\left(x_{2 m_{i}}, x_{2 n_{i}-1}\right)
$$

Taking the upper limit as $i \rightarrow \infty$ in the above inequalities, and using (3.7), (3.9), and (3.11) we get

$$
\limsup _{i \rightarrow \infty} d_{p_{b}}\left(x_{2 m_{i}}, x_{2 n_{i}}\right) \leq \varepsilon s
$$

and

$$
\limsup _{i \rightarrow \infty} d_{p_{b}}\left(x_{2 m_{i}+1}, x_{2 n_{i}-1}\right) \leq \varepsilon s^{2}
$$

From the definition of $d_{p_{b}}$ and (3.7), (3.10), (3.11), (3.12), and (3.13) we have the following relations:

$$
\begin{aligned}
& \frac{\varepsilon}{2 s} \leq \liminf _{i \rightarrow \infty} p_{b}\left(x_{2 m_{i}+1}, x_{2 n_{i}}\right), \\
& \limsup _{i \rightarrow \infty} p_{b}\left(x_{2 m_{i}}, x_{2 n_{i}-1}\right) \leq \frac{s \varepsilon}{2}, \\
& \limsup _{i \rightarrow \infty} p_{b}\left(x_{2 m_{i}}, x_{2 n_{i}}\right) \leq \frac{s \varepsilon}{2}, \\
& \limsup _{i \rightarrow \infty} p_{b}\left(x_{2 m_{i}+1}, x_{2 n_{i}-1}\right) \leq \frac{s^{2} \varepsilon}{2} .
\end{aligned}
$$


Since $x_{2 m_{i}} \in A$ and $x_{2 n_{i}-1} \in B$ are comparable, using (3.1) we have

$$
\begin{aligned}
& \psi\left(s^{2} p_{b}\left(x_{2 m_{i}+1}, x_{2 n_{i}}\right)\right) \\
& \quad=\psi\left(s^{2} p_{b}\left(f x_{2 m_{i}}, g x_{2 n_{i}-1}\right)\right) \\
& \quad \leq \psi\left(M_{s}\left(x_{2 m_{i}}, x_{2 n_{i}-1}\right)\right)-\varphi\left(M_{s}\left(x_{2 m_{i}}, x_{2 n_{i}-1}\right)\right)+L \psi\left(N\left(x_{2 m_{i}}, x_{2 n_{i}-1}\right)\right),
\end{aligned}
$$

where

$$
\begin{aligned}
M_{s}\left(x_{2 m_{i}}, x_{2 n_{i}-1}\right)= & \max \left\{p_{b}\left(x_{2 m_{i}}, x_{2 n_{i}-1}\right), p_{b}\left(x_{2 m_{i}}, x_{2 m_{i}+1}\right), p_{b}\left(x_{2 n_{i}-1}, x_{2 n_{i}}\right)\right. \\
& \left.\frac{p_{b}\left(x_{2 m_{i}}, x_{2 n_{i}}\right)+p_{b}\left(x_{2 m_{i}+1}, x_{2 n_{i}-1}\right)}{2 s}\right\}
\end{aligned}
$$

and

$$
\begin{aligned}
N\left(x_{2 m_{i}}, x_{2 n_{i}-1}\right)= & \min \left\{d_{p_{b}}\left(x_{2 m_{i}}, f x_{2 m_{i}}\right), d_{p_{b}}\left(x_{2 m_{i}}, g x_{2 n_{i}-1}\right), d_{p_{b}}\left(x_{2 n_{i}-1}, f x_{2 m_{i}}\right),\right. \\
& \left.d_{p_{b}}\left(x_{2 n_{i}-1}, g x_{2 n_{i}-1}\right)\right\} \\
= & \min \left\{d_{p_{b}}\left(x_{2 m_{i}}, x_{2 m_{i}+1}\right), d_{p_{b}}\left(x_{2 m_{i}}, x_{2 n_{i}}\right), d_{p_{b}}\left(x_{2 n_{i}-1}, x_{2 m_{i}+1}\right),\right. \\
& \left.d_{p_{b}}\left(x_{2 n_{i}-1}, x_{2 n_{i}}\right)\right\} .
\end{aligned}
$$

Taking the upper limit in (3.19) and (3.20), and using (3.7) and (3.14)-(3.17), we get

$$
\begin{aligned}
\limsup _{i \rightarrow \infty} M_{s}\left(x_{2 m_{i}}, x_{2 n_{i}-1}\right)= & \max \left\{\limsup _{i \rightarrow \infty} p_{b}\left(x_{2 m_{i}}, x_{2 n_{i}-1}\right), 0,0,\right. \\
& \left.\frac{\limsup _{i \rightarrow \infty} p_{b}\left(x_{2 m_{i}}, x_{2 n_{i}}\right)+\limsup \sup _{i \rightarrow \infty} p_{b}\left(x_{2 m_{i}+1}, x_{2 n_{i}-1}\right)}{2 s}\right\} \\
\leq & \max \left\{\frac{s \varepsilon}{2}, \frac{\frac{\varepsilon s+\varepsilon s^{2}}{2}}{2 s}\right\}=\frac{s \varepsilon}{2}
\end{aligned}
$$

and

$$
\limsup _{i \rightarrow \infty} N\left(x_{2 m_{i}}, x_{2 n_{i}-1}\right)=0 .
$$

Now, taking the upper limit as $i \rightarrow \infty$ in (3.18) and using (3.14), (3.21), and (3.22), we have

$$
\begin{aligned}
\psi\left(\frac{s \varepsilon}{2}\right) & =\psi\left(s^{2} \frac{\varepsilon}{2 s}\right) \leq \psi\left(s^{2} \limsup _{i \rightarrow \infty} p_{b}\left(x_{2 m_{i}+1}, x_{2 n_{i}}\right)\right) \\
& \leq \psi\left(\limsup _{i \rightarrow \infty} M_{s}\left(x_{2 m_{i}}, x_{2 n_{i}-1}\right)\right)-\varphi\left(\liminf _{i \rightarrow \infty} M_{s}\left(x_{2 m_{i}}, x_{2 n_{i}-1}\right)\right) \\
& \leq \psi\left(\frac{s \varepsilon}{2}\right)-\varphi\left(\liminf _{i \rightarrow \infty} M_{s}\left(x_{2 m_{i}}, x_{2 n_{i}-1}\right)\right)
\end{aligned}
$$

which implies that $\varphi\left(\liminf _{i \rightarrow \infty} M_{s}\left(x_{2 m_{i}}, x_{2 n_{i}-1}\right)\right)=0$. By (3.19), it follows that

$$
\liminf _{i \rightarrow \infty} p_{b}\left(x_{2 m_{i}}, x_{2 n_{i}}\right)=0
$$


which is in contradiction with (3.8). Thus, we have proved that $\left\{x_{n}\right\}$ is a $b$-Cauchy sequence in the metric space $\left(X, d_{p_{b}}\right)$. Since $\left(X, p_{b}\right)$ is $p_{b}$-complete, from Lemma $1.9,\left(X, d_{p_{b}}\right)$ is a $b$ complete $b$-metric space. Therefore, the sequence $\left\{x_{n}\right\}$ converges to some $z \in X$, that is, $\lim _{n \rightarrow \infty} d_{p_{b}}\left(x_{n}, z\right)=0$. Since $\lim _{m, n \rightarrow \infty} d_{p_{b}}\left(x_{n}, x_{m}\right)=0$, from the definition of $d_{p_{b}}$ and (3.7), we get

$$
\lim _{m, n \rightarrow \infty} p_{b}\left(x_{n}, x_{m}\right)=0
$$

Again, from Lemma 1.9,

$$
\lim _{n \rightarrow \infty} p_{b}\left(z, x_{n}\right)=\lim _{m, n \rightarrow \infty} p_{b}\left(x_{n}, x_{m}\right)=p_{b}(z, z)=0 .
$$

Step 3. In the above steps, we constructed an increasing sequence $\left\{x_{n}\right\}$ in $X$ such that $x_{n} \rightarrow z$, for some $z \in X$. As $A$ and $B$ are closed subsets of $X$, we have $z \in A \cap B$. Using the regularity assumption on $X$, we have $x_{n} \preceq z$, for all $n \in \mathbb{N}$. Now, we show that $f z=g z=z$. By (3.1), we have

$$
\begin{aligned}
\psi\left(s^{2} p_{b}\left(x_{2 n+1}, g z\right)\right) & =\psi\left(s^{2} p_{b}\left(f x_{2 n}, g z\right)\right) \\
& \leq \psi\left(M_{s}\left(x_{2 n}, z\right)\right)-\varphi\left(M_{s}\left(x_{2 n}, z\right)\right)+L \psi\left(N\left(x_{2 n}, z\right)\right),
\end{aligned}
$$

where

$$
\begin{aligned}
M_{s}\left(x_{2 n}, z\right) & =\max \left\{p_{b}\left(x_{2 n}, z\right), p_{b}\left(x_{2 n}, f x_{2 n}\right), p_{b}(z, g z), \frac{p_{b}\left(x_{2 n}, g z\right)+p_{b}\left(f x_{2 n}, z\right)}{2 s}\right\} \\
& =\max \left\{p_{b}\left(x_{2 n}, z\right), p_{b}\left(x_{2 n}, x_{2 n+1}\right), p_{b}(z, g z), \frac{p_{b}\left(x_{2 n}, g z\right)+p_{b}\left(x_{2 n+1}, z\right)}{2 s}\right\}
\end{aligned}
$$

and

$$
\begin{aligned}
N\left(x_{2 n}, z\right) & =\min \left\{d_{p_{b}}\left(x_{2 n}, f x_{2 n}\right), d_{p_{b}}(z, g z), d_{p_{b}}\left(z, f x_{2 n}\right), d_{p_{b}}\left(x_{2 n}, g z\right)\right\} \\
& =\min \left\{d_{p_{b}}\left(x_{2 n}, x_{2 n+1}\right), d_{p_{b}}(z, g z), d_{p_{b}}\left(z, x_{2 n+1}\right), d_{p_{b}}\left(x_{2 n}, g z\right)\right\} .
\end{aligned}
$$

Letting $n \rightarrow \infty$ in (3.24) and (3.25), and using Lemma 1.13, we get

$$
\limsup _{i \rightarrow \infty} M_{s}\left(x_{2 n}, z\right) \leq \max \left\{p_{b}(z, g z), \frac{s p_{b}(z, g z)}{2 s}\right\}=p_{b}(z, g z)
$$

and $N\left(x_{2 n}, z\right) \rightarrow 0$. Now, taking the upper limit as $n \rightarrow \infty$ in (3.23), and using Lemma 1.13 and (3.26) we get

$$
\begin{aligned}
\psi\left(s p_{b}(z, g z)\right) & =\psi\left(s^{2} \frac{1}{s} p_{b}(z, g z)\right) \leq \psi\left(s^{2} \limsup _{n \rightarrow \infty} p_{b}\left(x_{2 n+1}, g z\right)\right) \\
& \leq \psi\left(\limsup _{n \rightarrow \infty} M_{s}\left(x_{2 n}, z\right)\right)-\varphi\left(\liminf _{n \rightarrow \infty} M_{s}\left(x_{2 n}, z\right)\right) \\
& \leq \psi\left(s p_{b}(z, g z)\right)-\varphi\left(\liminf _{n \rightarrow \infty} M_{s}\left(x_{2 n}, z\right)\right) .
\end{aligned}
$$


It follows that $\varphi\left(\liminf _{n \rightarrow \infty} M_{s}\left(x_{2 n}, z\right)\right)=0$, and hence, by (3.24), that $p_{b}(z, g z)=0$. Thus, $z$ is a fixed point of $g$. On the other hand, from the first part of the proof, $f z=z$. Hence, $z$ is a common fixed point of $f$ and $g$.

Theorem 3.3 Let $\left(X, \preceq, p_{b}\right)$ be a $p_{b}$-complete ordered partial $b$-metric space and $A$ and $B$ be nonempty closed subsets of $X$. Let $f, g: X \rightarrow X$ be two $(A, B)$-weakly increasing mappings with respect to $\preceq$. Suppose that

$$
\psi\left(s^{2} p_{b}(f x, g y)\right) \leq \psi\left(M_{s}(x, y)\right)-\varphi\left(M_{s}(x, y)\right) .
$$

Also, let $f$ and $g$ be continuous. Then $f$ and $g$ have a common fixed point $z \in A \cap B$.

Proof Repeating the proof of Theorem 3.2, we construct an increasing sequence $\left\{x_{n}\right\}$ in $X$ such that $x_{n} \rightarrow z$, for some $z \in X$. As $A$ and $B$ are closed subsets of $X$, we have $z \in A \cap B$. Now, we show that $f z=g z=z$.

Using the triangular inequality, we get

$$
p_{b}(z, f z) \leq s p_{b}\left(z, f x_{2 n}\right)+s p_{b}\left(f x_{2 n}, f z\right)
$$

and

$$
p_{b}(z, g z) \leq s p_{b}\left(z, g x_{2 n+1}\right)+s p_{b}\left(g x_{2 n+1}, g z\right) .
$$

Letting $n \rightarrow \infty$ and using continuity of $f$ and $g$, we get

$$
\begin{aligned}
& p_{b}(z, f z) \leq s \lim _{n \rightarrow \infty} p_{b}\left(z, f x_{2 n}\right)+s \lim _{n \rightarrow \infty} p_{b}\left(f x_{2 n}, f z\right)=s p_{b}(f z, f z), \\
& p_{b}(z, g z) \leq s \lim _{n \rightarrow \infty} p_{b}\left(z, g x_{2 n+1}\right)+s \lim _{n \rightarrow \infty} p_{b}\left(g x_{2 n+1}, g z\right)=s p_{b}(g z, g z) .
\end{aligned}
$$

Therefore,

$$
\max \left\{p_{b}(z, f z), p_{b}(z, g z)\right\} \leq \max \left\{s p_{b}(f z, f z), s p_{b}(g z, g z)\right\} \leq s^{2} p_{b}(g z, f z)
$$

From (3.27) as $z \in A \cap B$, we have

$$
\psi\left(s^{2} p_{b}(f z, g z)\right) \leq \psi\left(M_{s}(z, z)\right)-\varphi\left(M_{s}(z, z)\right)
$$

where

$$
\begin{aligned}
M_{s}(z, z) & =\max \left\{p_{b}(z, z), p_{b}(z, f z), p_{b}(z, g z), \frac{p_{b}(z, g z)+p_{b}(z, f z)}{2 s}\right\} \\
& =\max \left\{p_{b}(z, f z), p_{b}(z, g z)\right\} .
\end{aligned}
$$

As $\psi$ is nondecreasing, we have $s^{2} p_{b}(f z, g z) \leq \max \left\{p_{b}(z, f z), p_{b}(z, g z)\right\}$. Hence, by (3.28) we obtain $s^{2} p_{b}(f z, g z)=\max \left\{p_{b}(z, f z), p_{b}(z, g z)\right\}$. But then, using (3.29), we get $\varphi\left(M_{s}(z\right.$, $z))=0$. Thus, we have $f z=g z=z$ and $z$ is a common fixed point of $f$ and $g$. 
As consequences, we have the following results.

By putting $A=B=X$ in Theorems 3.2 and 3.3 and $L=0$ in Theorem 3.2, we obtain the main results (Theorems 3 and 4) of Mustafa et al. [4].

Taking $\varphi=(1-\delta) \psi, 0<\delta<1$ in Theorem 3.2, we get the following.

Corollary 3.4 Let $\left(X, \preceq, p_{b}\right)$ be a $p_{b}$-complete ordered partial $b$-metric space and $A$ and $B$ be closed subsets of $X$. Let $f, g: X \rightarrow X$ be two $(A, B)$-weakly increasing mappings with respect to $\preceq$. Suppose that:

(a) $X=A \cup B$ is a cyclic representation of $X$ w.r.t. the pair $(f, g)$;

(b) there exist $0<\delta<1, L \geq 0$, and an altering distance function $\psi$ such that for any comparable elements $x, y \in X$ with $x \in A$ and $y \in B$, we have

$$
\psi\left(s^{2} p_{b}(f x, g y)\right) \leq \delta \psi\left(M_{s}(x, y)\right)+L \psi(N(x, y))
$$

where $M_{s}(x, y)$ and $N(x, y)$ are given by (3.2) and (3.3), respectively;

(c) $f$ and $g$ are continuous, or

(c') the space $\left(X, \preceq, p_{b}\right)$ is regular.

Then $f$ and $g$ have a common fixed point $z \in A \cap B$.

Taking $s=1$ and $L=0$ in Corollary 3.4, we obtain the partial version of Theorems 2.1 and 2.2 of Shatanawi and Postolache [12].

In Definitions 1.18 and 3.1 and Theorems 3.2 and 3.3, if we take $f=g$, then we have the following definitions and results.

Definition 3.5 Let $(X, \preceq)$ be a partially ordered set and $A$ and $B$ be closed subsets of $X$ with $X=A \cup B$. The mapping $f: X \rightarrow X$ is said to be $(A, B)$-weakly increasing if $f x \preceq f^{2} x$, for all $x \in A$ and $f y \preceq f^{2} y$, for all $y \in B$.

Definition 3.6 Let $\left(X, \preceq, p_{b}\right)$ be an ordered partial $b$-metric space, let $f: X \rightarrow X$ be a mapping, and let $A$ and $B$ be nonempty closed subsets of $X$. The mapping $f$ is called an ordered cyclic almost generalized weakly $(\psi, \varphi, L, A, B)$-contraction if

(1) $X=A \cup B$ is a cyclic representation of $X$ w.r.t. $f$; that is, $f A \subseteq B$ and $f B \subseteq A$;

(2) there exist two altering distance functions $\psi, \varphi$ and a constant $L \geq 0$, such that for arbitrary comparable elements $x, y \in X$ with $x \in A$ and $y \in B$, we have

$$
\psi\left(s^{2} p_{b}(f x, f y)\right) \leq \psi\left(M_{s}(x, y)\right)-\varphi\left(M_{s}(x, y)\right)+L \psi(N(x, y)),
$$

where

$$
M_{s}(x, y)=\max \left\{p_{b}(x, y), p_{b}(x, f x), p_{b}(y, f y), \frac{p_{b}(x, f y)+p_{b}(y, f x)}{2 s}\right\}
$$

and

$$
N(x, y)=\min \left\{d_{p_{b}}(x, f x), d_{p_{b}}(x, f y), d_{p_{b}}(y, f x), d_{p_{b}}(y, f y)\right\} .
$$


Corollary 3.7 Let $\left(X, \preceq, p_{b}\right)$ be a $p_{b}$-complete ordered partial b-metric space and $A$ and $B$ be two nonempty closed subsets of $X$. Let $f: X \rightarrow X$ be a $(A, B)$-weakly increasing mapping with respect to $\preceq$. Suppose that the mapping $f$ is an ordered cyclic almost generalized weakly $(\psi, \varphi, L, A, B)$-contraction. Then $f$ has a fixed point $z \in A \cap B$.

Corollary 3.8 Let $\left(X, \preceq, p_{b}\right)$ be a $p_{b}$-complete ordered partial b-metric space and $A$ and $B$ be nonempty closed subsets of $X$. Let $f: X \rightarrow X$ be a $(A, B)$-weakly increasing mapping with respect to $\preceq$. Suppose that

$$
\psi\left(s^{2} p_{b}(f x, f y)\right) \leq \psi\left(M_{s}(x, y)\right)-\varphi\left(M_{s}(x, y)\right) .
$$

Also, let $f$ be continuous. Then $f$ has a fixed point $z \in A \cap B$.

We illustrate our results with the following example.

Example 3.9 Consider the partial $b$-metric space $X=[0,6]$ by $p_{b}(x, y)=[\max \{x, y\}]^{2}$. Define an order $\preceq$ on $X$ by

$$
x \preceq y \quad \Longleftrightarrow \quad x=y \vee(x, y \in[0,1] \wedge x \geq y)
$$

Obviously, $\left(X, \preceq, p_{b}\right)$ is a $p_{b}$-complete ordered $p_{b}$-metric space. Indeed, if we have $\lim _{n, m \rightarrow \infty} p_{b}\left(x_{n}, x_{m}\right)=u$, for some $u \in[0, \infty)$, then we have

$$
\begin{aligned}
\lim _{m, n \rightarrow \infty}\left(\max \left\{x_{n}, x_{m}\right\}\right)^{2}=u & \Longrightarrow \max \left\{\left(\lim _{n \rightarrow \infty} x_{n}\right)^{2},\left(\lim _{m \rightarrow \infty} x_{m}\right)^{2}\right\}=u \\
& \Longrightarrow\left(\lim _{n \rightarrow \infty} x_{n}\right)^{2}=\left(\lim _{m \rightarrow \infty} x_{m}\right)^{2}=u
\end{aligned}
$$

So, we have $\lim _{n \rightarrow \infty} x_{n}=\sqrt{u}$, which convergence holds in the case of the usual metric in $X$. Now, it is easy to see that $\lim _{n, m \rightarrow \infty} p_{b}\left(x_{n}, x_{m}\right)=\lim _{n \rightarrow \infty} p_{b}\left(x_{n}, \sqrt{u}\right)=p_{b}(\sqrt{u}, \sqrt{u})=u$.

Let $f: X \rightarrow X$ be given by

$$
f x= \begin{cases}\frac{x^{2}}{3(1+x)}, & x \in[0,1], \\ \frac{x}{6}, & x>1,\end{cases}
$$

$\psi(t)=t$ and $\varphi(t)=\frac{8}{9} t$ for all $t \in[0, \infty)$. Also, let $A=[0,1]$ and $B=[0,6]$. In order to check the conditions of Corollary 3.8, take $x, y \in X$ such that $x \preceq y$ and consider the following two possible cases.

$1^{\circ} x \leq 1$. Then obviously also $y \leq 1$ and $x \geq y$. It is easy to check that

$$
\begin{aligned}
2^{2} p_{b}(f x, f y) & =4\left[\max \left\{\frac{x^{2}}{3(1+x)}, \frac{y^{2}}{3(1+y)}\right\}\right]^{2} \\
& =4\left[\frac{x^{2}}{3(1+x)}\right]^{2}=4\left[\frac{x}{3(1+x)} \cdot x\right]^{2} \leq 4\left[\frac{x}{6}\right]^{2} \\
& =\frac{1}{9} p_{b}(x, y) \\
& \leq M_{s}(x, y)-\varphi\left(M_{s}(x, y)\right) .
\end{aligned}
$$


$2^{\circ} x>1$. Then $x=y>1$ and

$$
\begin{aligned}
2^{2} p_{b}(f x, f y) & =4\left[\max \left\{\frac{x}{6}, \frac{y}{6}\right\}\right]^{2}=4\left[\frac{y}{6}\right]^{2} \\
& =\frac{1}{9} p_{b}(x, y) \\
& \leq p_{b}(x, y) \\
& \leq M_{s}(x, y)-\varphi\left(M_{s}(x, y)\right) .
\end{aligned}
$$

Hence, all the conditions of Corollary 3.8 are satisfied and $f$ has a fixed point (which is $z=0)$.

\section{Competing interests}

The authors declare that they have no competing interests.

\section{Authors' contributions}

All authors contributed equally and significantly in writing this paper. All authors read and approved the final manuscript.

\section{Author details}

'Department of Mathematics, King Abdulaziz University, P.O. Box 80203, Jeddah, 21589, Saudi Arabia. ${ }^{2}$ Department of Mathematics, Qaemshahr Branch, Islamic Azad University, Qaemshahr, Iran. ${ }^{3}$ Department of Mathematics, Gilan-E-Gharb Branch, Islamic Azad University, Gilan-E-Gharb, Iran.

\section{Acknowledgements}

This article was funded by the Deanship of Scientific Research (DSR), King Abdulaziz University. The authors, therefore, acknowledge with thanks DSR for technical and financial support.

Received: 7 March 2014 Accepted: 8 August 2014 Published: 3 September 2014

\section{References}

1. Czerwik, S: Contraction mappings in b-metric spaces. Acta Math. Inform. Univ. Ostrav. 1, 5-11 (1993)

2. Matthews, SG: Partial metric topology. In: General Topology and Its Applications, Proc. 8th Summer Conf., Queen's, College, 1992. Annals of the New York Academy of Sciences, vol. 728, pp. 183-197 (1994)

3. Shukla, S: Partial b-metric spaces and fixed point theorems. Mediterr. J. Math. (2014). doi:10.1007/s00009-013-0327-4

4. Mustafa, Z, Roshan, JR, Parvaneh, V, Kadelburg, Z: Some common fixed point results in ordered partial $b$-metric spaces. J. Inequal. Appl. 2013, 562 (2013)

5. Kirk, WA, Srinivasan, PS, Veeramani, P: Fixed points for mappings satisfying cyclical contractive conditions. Fixed Point Theory 4(1), 79-89 (2003)

6. Berinde, V: General constructive fixed point theorems for Ćirić-type almost contractions in metric spaces. Carpath. J. Math. 24, 10-19 (2008)

7. Berinde, V: Some remarks on a fixed point theorem for Ćirić-type almost contractions. Carpath. J. Math. 25, 157-162 (2009)

8. Babu, GVR, Sandhya, ML, Kameswari, MVR: A note on a fixed point theorem of Berinde on weak contractions. Carpath J. Math. 24, 8-12 (2008)

9. Ćirić, L, Abbas, M, Saadati, R, Hussain, N: Common fixed points of almost generalized contractive mappings in ordered metric spaces. Appl. Math. Comput. 217, 5784-5789 (2011)

10. Aghajani, A, Radenović, S, Roshan, JR: Common fixed point results for four mappings satisfying almost generalized $(S, T)$-contractive condition in partially ordered metric spaces. Appl. Math. Comput. 218, 5665-5670 (2012)

11. Khan, MS, Swaleh, M, Sessa, S: Fixed point theorems by altering distances between the points. Bull. Aust. Math. Soc. 30, 1-9 (1984)

12. Shatanawi, W, Postolache, M: Common fixed point results of mappings for nonlinear contraction of cyclic form in ordered metric spaces. Fixed Point Theory Appl. 2013, 60 (2013). doi:10.1186/1687-1812-2013-60

13. Hussain, $N$, Parvaneh, $V$, Roshan, JR, Kadelburg, Z: Fixed points of cyclic weakly $(\psi, \varphi, L, A, B)$-contractive mappings in ordered $b$-metric spaces with applications. Fixed Point Theory Appl. 2013, 256 (2013)

14. Samet, B, Vetro, C, Vetro, P: Fixed point theorem for $\alpha$ - $\psi$-contractive type mappings. Nonlinear Anal. 75, 2154-2165 (2012)

15. Berinde, V: Contracţii generalizate şi aplicaţii. Editura Club Press 22, Baia Mare (1997)

16. Berinde, V: Sequences of operators and fixed points in quasimetric spaces. Stud. Univ. Babeş-Bolyai, Math. 16(4), 23-27 (1996)

17. Berinde, V: Generalized contractions in quasimetric spaces. In: Seminar on Fixed Point Theory. Preprint, vol. 3, pp. 3-9 (1993)

18. Karapinar, E, Kumam, P, Salimi, P: On $\alpha$ - $\psi$-Meir-Keeler contractive mappings. Fixed Point Theory Appl. 2013,94 (2013)

19. Rus, IA: Generalized Contractions and Applications. Cluj University Press, Cluj-Napoca (2001) 
doi:10.1186/1029-242X-2014-345

Cite this article as: Latif et al.: Fixed point results via $\alpha$-admissible mappings and cyclic contractive mappings in partial b-metric spaces. Journal of Inequalities and Applications 2014 2014:345.

Submit your manuscript to a SpringerOpen ${ }^{\circ}$ journal and benefit from:

- Convenient online submission

- Rigorous peer review

- Immediate publication on acceptance

Open access: articles freely available online

- High visibility within the field

- Retaining the copyright to your article

Submit your next manuscript at $\boldsymbol{s p r i n g e r o p e n . c o m ~}$ 